\title{
POTENCIAL DE LINHAGENS ORIUNDAS DE POPULAÇÕES DE MILHO BRAQUÍTICO PARA OBTENÇÃO DE HÍBRIDOS
}

\author{
BELISA CRISTINA SAITO ${ }^{1}$ e JOÃO ANTONIO DA COSTA ANDRADE${ }^{1}$
}

${ }^{1}$ UNESP - Campus de Ilha Solteira,SP, Brasil, belisasaito@gmail.com, jandrade@bio.feis.unesp.br

Revista Brasileira de Milho e Sorgo, v.16, n.1, p. 120-130, 2017

\begin{abstract}
RESUMO - O objetivo do trabalho foi a identificar linhagens com alta capacidade de combinação visando o desenvolvimento de híbridos simples adaptados à condição de elevada densidade populacional de plantas. Treze linhagens originadas de duas populações de milho braquítico foram cruzadas seguindo o esquema de dialelo parcial (6x7). Os híbridos simples foram avaliados em duas safras (primeira e segunda safras). Os efeitos da interação entre as capacidades gerais de combinação (CGC) e safras foram diferentes para rendimento de grãos apenas para linhagens Isanão-VD1, enquanto que para a altura de plantas, altura de espigas e acamamento mais quebramento os efeitos da interação CGCs x safras foram diferentes para ambos os grupos de linhagens. Levando em consideração apenas o rendimento de grãos, os melhores híbridos são esperados entre as linhagens IVF1-5 e IVF1-10 da população Isanão VF1 e IVD1-1 e IVD1-2 da população Isanão-VD1. Considerando-se todos os caracteres, as linhagens promissoras para a primeira safra são IVF1-6, IVD1-1 e IVD1-5, e para a segunda safra as linhagens são IVF1-10, IVD1-8 e IVD19. Os híbridos mais adequados são IVF1-10 x IVD1-5 para primeira safra e IVF1-10 x IVD1-8 e IVF1-10 xIVD1-9 para a segunda.
\end{abstract}

Palavras-chave: dialelo parcial, capacidade geral de combinação, capacidade específica de combinação.

\section{POTENTIAL OF INBRED LINES DERIVED FROM BRACHYTIC MAIZE POPULATIONS FOR OBTAINING HYBRIDS}

\begin{abstract}
The objective of this study was to identify parents with high combining ability aiming at the development of outstanding hybrids. Thirteen inbred lines originated of two brachytic maize populations were crossed following the partial diallel (6x7) scheme. The single-cross hybrids were evaluated in two crop seasons (regular crop and second crop). The effects of interaction general combining abilities (GCAs) x seasons were different for yield only for lines of Isanão-VD-1, while for plant height, ear height and stalk lodging and breaking, the effects of interaction GCAs x seasons were different for both groups of lines. Taking into account only the grain yield, the best hybrids are expected between the inbred lines IVF1-5, and IVF1-10, of the population Isanão-VF1 and IVD1-1 and IVD1-2 and IVD1-5 of the population Isanão-VD1. Considering all the traits, the inbred lines promising for the first crop are IVF1-6, IVD1-1 and IVD1-5 and for the second crop are the inbred lines IVF1-10, IVD1-8 and IVD1-9. The most suitable hybrids are IVF1-10 x IVD1-5 for the first crop and IVF1-10 x IVD1-8, and IVF1-10 xIVD1-9 for second crop.
\end{abstract}

Keywords: partial diallel, general combining ability, specific combining ability. 
Em programas de melhoramento de milho, é necessário identificar linhagens com melhor desempenho em combinações híbridas. A avaliação das linhagens quanto à capacidade de combinação é a etapa mais trabalhosa, e o método dos cruzamentos dialélicos é amplamente utilizado pelos melhoristas (Guimarães et al., 2007). Como mencionado por Cruz et al. (2012), o termo dialelo é usado para expressar um conjunto de híbridos, resultante do cruzamento entre os genitores, que podem ser linhagens, variedades ou clones, podendo ou não incluir os respectivos pais, os híbridos recíprocos e ainda outras gerações relacionadas.

Diversos estudos sobre a seleção dos melhores genitores foram desenvolvidos, destacando-se os cruzamentos dialélicos, que permitem estimar as capacidades geral (CGC) e específica (CEC) de combinação. Cruz e Vencovsky (1989) afirmaram que os cruzamentos mais promissores são aqueles que apresentam CEC de magnitudes elevadas (positivas ou negativas, dependendo do caráter) e que sejam provenientes do cruzamento de genitores divergentes, em que pelo menos um deles apresente elevada CGC. De acordo com Jung et al. (2007), um dos esquemas dialélicos mais empregados é o de Griffing (1956), que gera informações a respeito da concentração de genes com efeitos predominantemente aditivos, o que resulta em altos valores de CGC e de CEC, sendo esta devida aos efeitos não aditivos. Os esquemas dialélicos de cruzamento foram adaptados, visando obter informações do cruzamento entre dois grupos de linhagens de origem diferente, buscando identificar bons híbridos simples que cada vez mais são utilizados na agricultura brasileira (Cruz et al., 2013).

O objetivo deste trabalho foi selecionar linhagens com boa capacidade de combinação para obtenção de híbridos simples adaptados à situação de elevada densidade populacional, com o uso de dialelo parcial, a partir de seis linhagens braquíticas oriundas da população Isanão-VF1 e sete linhagens braquíticas oriundas da população Isanão-VD1.

\section{Material e Métodos}

As atividades experimentais foram desenvolvidas na Fazenda de Ensino, Pesquisa e Extensão da Unesp - Campus de Ilha Solteira, localizada no município de Selvíria-MS (20²0’ S, 51 ${ }^{\circ} 23^{\prime}$ O e altitude de $335 \mathrm{~m}$ ). O clima predominante da região, conforme classificação de Köppen, é do tipo Aw, definido como tropical úmido com estação chuvosa no verão e seca no inverno. A precipitação pluvial média anual é de $1.330 \mathrm{~mm}$, com temperatura do ar média anual de aproximadamente $25{ }^{\circ} \mathrm{C}$ e umidade relativa do ar média anual de 66\% (Centurion, 1982). O solo local foi classificado por Demattê (1980) e reclassificado segundo o Sistema Brasileiro de Classificação de Solos (Sistema..., 1999) como Latossolo vermelho distrófico $(\mathrm{LVd})$.

Foram avaliados 42 híbridos resultantes de cruzamentos entre seis linhagens oriundas da população Isanão-VF1 (IVF1) e sete linhagens oriundas da população Isanão-VD1 (IVD1), populações braquíticas obtidas em Ilha Solteira-SP (Candido \& Andrade, 2008). Os híbridos experimentais mais a testemunha DOW2B688 foram avaliados em delineamento de blocos casualizados com três repetições, em sistema de semeadura direta, em primeira e segunda safra (outubro de 2011 e março de 2011, respectivamente), distribuindo-se o dobro do número de sementes necessário, com desbaste no estádio de seis folhas plenamente desenvolvidas. Cada parcela foi composta por duas linhas de $5 \mathrm{~m}$ com espaçamento de $0,45 \mathrm{~m} \mathrm{e}$ população de 80.000 plantas.ha $^{-1}$. 
Foram avaliados os caracteres rendimento de

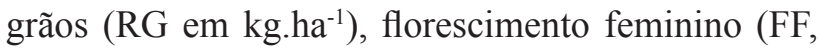
em dias), altura de plantas (AP, em cm), altura de espigas $(\mathrm{AE}$, em $\mathrm{cm})$, prolificidade ( $\mathrm{PRO}$, em espigas planta $^{-1}$ ), acamamento mais quebramento (ACQ, em plantas.parcela-1). Os caracteres PRO, ACQ e RG foram corrigidos para 36 plantas por parcela pela análise de covariância com o estande, como descrito em Vencovsky e Barriga (1992). O RG também foi corrigido para $13 \%$ de umidade e transformado para kg.ha- ${ }^{-1}$.

As análises estatísticas foram realizadas utilizando-se o programa Genes (Cruz, 2001), para cada safra, incluindo a testemunha (dados não apresentados) para confirmação da homogeneidade dos quadrados médios residuais. A ausência de normalidade dos erros ocorreu apenas para ACQ, que foi analisado novamente como, o que foi suficiente para que os erros apresentassem distribuição normal, permitindo tanto a análise estatística conjunta (dados não apresentados), como a análise dialélica conjunta, após as análises individuais.

A análise dialélica, para cada safra, foi realizada de acordo com o modelo II de Griffing (1956), adaptado para dialelos parciais cujo modelo é $Y_{i j}=\mu+g_{i}+g_{j}+s_{i j}+\varepsilon_{i j}$, onde $Y_{i j}$ : rendimento médio do híbrido entre a linhagem $i$ e a linhagem $j$; $\mu$ : média geral do dialelo; $g_{i}$ : efeito da capacidade geral de combinação (CGC) da linhagem $i ; g_{j}$ : efeito da capacidade geral de combinação da linhagem $j ; s_{i j}$ : efeito da capacidade específica de combinação (CEC) do híbrido $i j$; $\varepsilon_{i j}$ erro experimental associado à observação do híbrido $i j$. A análise dialélica conjunta, adaptada do modelo II de Griffing (1956) foi feita utilizando-se o modelo $Y_{i j k}=\mu+e_{k}+g_{i}+g_{j}+s_{i j}+(g e)_{i k}+(g e)_{j k}+(s e)_{i j k}+\varepsilon_{i j k}$, onde $Y_{i j k}$ : rendimento médio do híbrido entre a linha- gem $i$ e a linhagem $j$, na safra $k$; $\mu$ : média geral dos híbridos experimentais envolvidos, considerando as duas safras; $e_{k}$ : efeito da safra $k ; g_{i}$ : efeito da capacidade geral de combinação da linhagem $i$ (população Isanão-VF1); $g_{j}$ : efeito da capacidade geral de combinação da linhagem $j$ (população Isanão-VD1); $S_{i j}$ : efeito da capacidade específica de combinação do híbrido $i j$; $(g e)_{i k}$ : efeito da interação da capacidade geral de combinação de combinação da linhagem $i$ (população Isanão-VF1) com a safra $k$; $(g e)_{j k}$ : efeito da interação da capacidade geral de combinação da linhagem $j$ (população Isanão-VD1) com o safra $k$; $(s e)_{i j k}$ : efeito da interação da capacidade específica de combinação do híbrido $i j$ com a safra $k$; $\varepsilon_{i j k}$ erro experimental associado à média do híbrido ij na safra $k$.

\section{Resultados e Discussão}

As diferenças entre híbridos foram significativas para todos os caracteres e a análise dialélica conjunta evidenciou teste $\mathrm{F}$ significativo para safras para os caracteres RG, FF, AP, AE e ACQ (Tabela 1), o que era esperado em razão das condições climáticas muito diferentes e também verificado por Bento et al. (2003). O teste F da interação híbridos x safras foi significativo para RG, FF, AP, AE e ACQ, evidenciando que as safras influenciaram os híbridos de maneira diferente para esses caracteres, o que também foi observado por Beck et al. (1990) que, além da interação entre genótipos e locais, também observaram significância da interação CGC x safras, para RG, FF, AP e AE.

Ocorreram diferenças significativas para os efeitos principais de CGC para RG, FF e PRO, quando se consideraram as linhagens IVF1, sendo que a interação dessas CGCs com safras não foi significativa. A interação CGC x safras foi significativa para AP, 
Tabela 1. Quadrados médios da análise de variância e da análise dialélica para os caracteres rendimento de grãos de milho ( $\mathrm{RG}$, em kg.parcela ${ }^{-1}$ ), florescimento feminino ( $\mathrm{FF}$, em dias), altura de plantas (AP, em $\mathrm{cm}$ ), altura de espigas (AE, em cm), acamamento mais quebramento [ACQ, em ] e prolificidade (PRO, em plantas. parcela $\left.^{-1}\right)$, em duas safras, em Selvíria-MS.

\begin{tabular}{lccccccc}
\hline FV & GL & RG & FF & AP & AE & ACQ & PRO \\
\hline \multicolumn{7}{c}{ Análise conjunta para as duas safras } \\
SAFRAS (S) & 1 & $299447463^{* *}$ & $6789,13^{* *}$ & $22289,29 * *$ & $8563,33^{* *}$ & $142,995^{* *}$ & 0,003 \\
HÍBRIDOS (H) & 41 & $2001620^{* *}$ & $5,26^{* *}$ & $366,45^{* *}$ & $312,28^{* *}$ & $0,976^{* *}$ & $0,014^{* *}$ \\
CGC IVF1 & 5 & $3550511^{* *}$ & $9,92^{* *}$ & $436,86^{*}$ & 190,59 & $4,024^{* *}$ & $0,036^{* *}$ \\
CGC IVD1 & 6 & $4051138^{* *}$ & $14,28^{* *}$ & $604,53^{* *}$ & $1120,23^{* *}$ & 0,452 & 0,008 \\
CEC & 30 & 1333567 & 2,68 & $307,10^{*}$ & 170,97 & 0,572 & $0,012^{*}$ \\
H x S & 41 & $1379741^{*}$ & $4,95^{* *}$ & $751,99^{* *}$ & $373,52^{* *}$ & $1,186^{* *}$ & 0,009 \\
CGC IVF1 x S & 5 & 991630 & 4,68 & $1340,70^{* *}$ & $432,45^{* *}$ & $3,414^{* *}$ & 0,012 \\
CGC IVD1 x S & 6 & $3538602^{* *}$ & $11,12^{* *}$ & $588,84^{* *}$ & $774,73^{* *}$ & $1,715^{* *}$ & 0,007 \\
CEC x S & 30 & 1012653 & 3,76 & $686,50^{* *}$ & $283,46^{* *}$ & 0,708 & 0,009
\end{tabular}

Desdobramento das interações significativas

\begin{tabular}{|c|c|c|c|c|c|c|c|}
\hline CGC IVF1/S1 & 5 & ----- & ----- & $1225,17 * *$ & $482,02 * *$ & 0,42 & ----- \\
\hline CGC IVF1/S2 & 5 & ----- & ----- & $552,39 * *$ & 141,02 & $7,018 * *$ & ----- \\
\hline CGC IVD1/S1 & 6 & $6488848 * *$ & $21,44 * *$ & 342,98 & $1511,65^{* *}$ & 0,489 & ----- \\
\hline CGC IVD1/S2 & 6 & 1100892 & 3,96 & $850,39 * *$ & $383,31 * *$ & $1,677 * *$ & ----- \\
\hline $\mathrm{CEC} / \mathrm{S} 1$ & 30 & ----- & ----- & $325,06 * *$ & 167,41 & ----- & - \\
\hline $\mathrm{CEC} / \mathrm{S} 2$ & 30 & ----- & ----- & $668,54 * *$ & $287,02 * *$ & ----- & ----- \\
\hline ERRO MÉDIO & 164 & 935125 & 2,69 & 162,05 & 123,94 & 0,479 & ----- \\
\hline CV (\%) & & 17,02 & 2,88 & 6,52 & 10,17 & 34,19 & 9,12 \\
\hline Médias & & 5678,53 & 56,89 & 195,13 & 109,46 & 2,024 & 0,917 \\
\hline
\end{tabular}

**, * Significativo a 1\% e 5\% de probabilidade pelo teste F. 
AE e ACQ no grupo IVF1 e para todos os caracteres, exceto PRO, no grupo IVD1, indicando a necessidade do desdobramento dos efeitos da CGC dentro de safras (Tabela 1). Nevado e Cross (1990), avaliando três dialelos de oito sintéticos em nove ambientes por três anos, também observaram significância da interação entre genótipos e ambientes para rendimento de grãos, número de espigas por planta, peso de 200 grãos e número de grãos por fileira. Havendo interação para RG no grupo de linhagens IVD1 é possível a existência de linhagens particularmente com melhor desempenho em uma das safras, na obtenção dos híbridos, o que não ocorreu para o grupo de linhagens IVF1.

Os efeitos da CGC para AP diferiram significativamente nas duas safras no grupo IVF1 e apenas na segunda safra no grupo IVD1, enquanto que para AE apenas o grupo IFV1 na segunda safra não apresentou diferenças significativas. Isso se deve ao fato de que as condições ambientais da primeira e da segunda safra influenciaram de maneira diferente os locos de efeito aditivo para AP e AE nos dois grupos. Santos et al. (2013), avaliando 28 progênies provenientes de híbridos comerciais, utilizando o Método 4 de Griffing (1956), modelo 1, também encontraram diferenças significativas nos efeitos da CGC para AP e AE, evidenciando que os efeitos aditivos estão predominantemente envolvidos na expressão desses caracteres, mas também sujeitos à ação diferente do ambiente, provocando interação significativa. Para ACQ, as condições da primeira safra não permitiram discriminação entre os efeitos da CGC tanto no grupo IVF1 como IVD1 (Tabela 1).

A ocorrência de interação para RG apenas no grupo IVD1 (Tabela 1) é uma evidência da diferença de sensibilidade dos genes de efeito aditivo dos dois grupos às condições de cada ambiente. Isso fica mais evidente ainda pela não significância dos efeitos da
CGC das linhagens do grupo IVD1 na segunda safra, em que as condições foram mais estressantes. Entende-se que muitos locos com expressão significativa na primeira safra não se expressaram na segunda safra, em relação aos efeitos aditivos de seus alelos. Sendo assim, as melhores linhagens para obtenção de híbridos para a primeira safra também poderão ser indicadas para a segunda. Essas mesmas considerações podem ser extrapoladas para FF no grupo de linhagens IVD1.

Os efeitos da CEC, considerados conjuntamente, não foram diferentes para RG, FF, AE e ACQ, indicando a menor importância dos efeitos gênicos não aditivos, como encontrado por Fidelis et al. (2010), embora a interação com safras tenha sido significativa para AE (Tabela 1). Para RG isso também foi observado por Hallauer e Miranda Filho (1995), Gorgulho e Miranda Filho (2001) e Morello et al. (2001). No entanto, estes autores trabalharam com genitores de base genética ampla, em que os efeitos da CGC normalmente são mais importantes do que os da CEC. Para AP, os efeitos não aditivos são importantes, mas são influenciados diferentemente pelas condições das duas safras, evidenciado pela interação significativa, embora o desdobramento também indique significância desses efeitos para ambas as safras. Esses resultados são diferentes daqueles obtidos, para um grupo de nove linhagens, por Nihei e Ferreira (2012) para AE, mas concordantes quanto a AP.

As linhagens IVF1 que apresentaram CGC conjunta positiva para RG (Tabela 2) foram IVF15, IVF1-6 e IVF1-10, enquanto IVD1-1, IVD1-2 e IVD1-5 foram as melhores do grupo IVD1 na primeira safra e equivalentes às demais na segunda safra. Nota-se que essas linhagens IVD1 se destacaram por apresentar maiores estimativas de CGC quando comparadas com as linhagens IVF1. Essas linhagens com 
maior CGC possuem maior concentração de alelos favoráveis para aumento do RG e podem ser indicadas para ambas as safras, pois não houve interação com safras no grupo IVF1 e a interação presente no grupo IVD1 é de natureza simples, por causa apenas da similaridade dos efeitos da CGC na segunda safra.

Para a precocidade, nas estimativas conjuntas (Tabela 2), destacaram-se duas linhagens IVF1 (interação não significativa com safras). No grupo IVD1, na primeira safra (interação significativa) foram três com estimativas negativas e significativamente diferentes de zero para CGC, mas foram equivalentes às demais na segunda safra. A maior tendência de diminuição do ciclo ocorreu nas linhagens IVF1-5 e IVD1- 9.

$\mathrm{Na}$ primeira safra, para AP, a linhagem com CGC favorável para a diminuição desse caráter para o grupo de linhagens IVF1 foi IVF1-4. Para AE, isso ocorreu para a linhagem IVF1-4 do grupo das IVF1 e as linhagens IVD1-1, IVD1-4 e IVD1-9 pertencentes ao grupo IVD1. Na segunda safra, a linhagem IVD19 apresentou a melhor CGC para os dois caracteres. Segundo Farinelli et al. (2003), genótipos com baixos valores de altura de plantas e de espigas possuem grande potencial para cultivo em populações adensadas em virtude da disposição anatômica das folhas, o que também foi observado por Kappes et al. (2011) no híbrido AG9010.

Houve diferenças das CGC para ACQ, de ambos os grupos, apenas para a segunda safra (Tabela 1). A linhagem com melhor CGC foi IVF1-1 (-0,598), seguida da IVD1-8 $(-0,405)$. Outras cinco linhagens apresentaram estimativas de CGC favoráveis para a diminuição do caráter, sendo elas IVF1-2, IVF1-4, IVF1-5, IVD1-4 e IVD1-9, porém com valores não significativamente diferentes de zero. Como na primeira safra não houve diferença significativa, enten- de-se que as linhagens selecionadas na segunda safra tenham as mesmas qualidades para a primeira safra em termos de concentração de alelos ativos para diminuição do caráter.

Para PRO, as melhores estimativas conjuntas da CGC (interação não significativa para ambos os conjuntos de linhagens) ocorreram para as linhagens IVF1-5, IVF1-1 e IVF1-6, porém com estimativas não diferentes de zero pelo teste t. No grupo IVD1, as estimativas foram estatisticamente iguais. Locatelli et al. (2002), avaliando PRO em nove linhagens endogâmicas, também não encontraram grandes diferenças para esse caráter.

Sempre que possível, a estratégia será a busca por linhagens mais precoces e com melhor arquitetura, com base em FF, AP, AE e ACQ. Considerando todos os caracteres em que a CGC foi significativa para o grupo IVF1, além das interações com safras, na primeira safra, as linhagens IVF1-5 e IVF1-6 são as que mais se aproximam das condições de interesse, uma vez que a perfeição para todos os caracteres não será possível. No caso de IVF1-5 apenas para AE e ACQ (não significativos) a linhagem não se coloca entre as melhores. No caso de IVF1-6 isso ocorre apenas para FF e AP. Na maioria desses casos, são interessantes as estimativas da CGC mais baixas ou que não sejam diferentes das demais. Exceção é o caso da AP para a linhagem IVF1-6, que, entretanto, apresenta condição favorável para AE nas duas safras (Tabela 2), o que é mais importante em termos de arquitetura para suportar altas densidades populacionais. Portanto, estas podem ser eleitas as linhagens com melhores características gerais para confecção de híbridos com as linhagens do grupo IVD1, embora as estimativas não difiram de zero pelo teste t. Ainda para a primeira safra, para o grupo IVD1, considerando todos os caracteres e as interações com safras, a linhagem IVD1-1 
Tabela 2. Estimativas das Capacidades Gerais de Combinação das 13 linhagens oriundas dos compostos IsanãoVF1 e Isanão-VD1, para os caracteres rendimento de grãos o (RG, em kg.parcela $\left.{ }^{-1}\right)$, florescimento feminino (FF, em dias), altura de plantas (AP, em $\mathrm{cm}$ ), altura de espigas (AE, em $\mathrm{cm}$ ), acamamento mais quebramento $\left(A C Q\right.$, em $\left(\left(\text { plantas.parcela }^{-1}\right)\right)^{0,5}$ e prolificidade (PRO, em espigas.planta $\left.{ }^{-1}\right)$, para primeira e segunda safras, em Selvíria-MS.

\begin{tabular}{|c|c|c|c|c|c|c|}
\hline Linhagem & $\mathrm{RG}$ & FF & $\mathrm{AP}$ & $\mathrm{AE}$ & ACQ & PRO \\
\hline \multicolumn{7}{|c|}{ Primeira safra } \\
\hline IVF1-1 & -144 & 0,21 & 1,04 & $-2,19$ & $-0,069$ & 0,018 \\
\hline IVF1-2 & -340 & $-0,37$ & 6,61 & 3,10 & $-0,203$ & $-0,034$ \\
\hline IVF1-4 & $-596^{*}$ & 0,68 & $-13,25 * *$ & $-7,48^{*}$ & 0,017 & $-0,048^{*}$ \\
\hline IVF1-5 & 308 & $-1,13^{*}$ & $-4,20$ & 0,81 & 0,23 & $0,057^{*}$ \\
\hline IVF1-6 & 398 & 0,02 & 3,18 & $-0,81$ & $-0,003$ & 0,015 \\
\hline IVF1-10 & 375 & 0,59 & 6,61 & $6,57 *$ & 0,028 & $-0,006$ \\
\hline IVD1-1 & $521^{*}$ & $-0,92$ & $-0,75$ & $-10,56^{* *}$ & 0,057 & $-0,017$ \\
\hline IVD1-2 & 479 & $1,47 *$ & 6,75 & 4,05 & 0,017 & $-0,036$ \\
\hline IVD1-3 & $-492 *$ & $-0,75$ & $-0,25$ & 0,83 & $-0,035$ & 0,02 \\
\hline IVD1-4 & $-803 * *$ & $-0,42$ & $-7,31$ & $-7,23 *$ & 0,188 & $-0,004$ \\
\hline IVD1-5 & $740 *$ & $1,47^{*}$ & 2,91 & $13,66^{* *}$ & $-0,316$ & $-0,012$ \\
\hline IVD1-8 & 32 & 0,25 & 0,97 & $7,88^{*}$ & 0,143 & 0,027 \\
\hline IVD1-9 & -476 & $-1,09^{*}$ & $-2,31$ & $-8,62 *$ & $-0,054$ & 0,02 \\
\hline \multicolumn{7}{|c|}{ Segunda safra } \\
\hline IVF1-1 & -154 & 0,49 & $-6,67^{*}$ & $-2,77$ & $-0,598^{*}$ & 0,039 \\
\hline IVF1-2 & -3 & $-0,27$ & $-0,96$ & $-0,96$ & $-0,298$ & $-0,011$ \\
\hline IVF1-4 & -250 & 0,21 & 2,85 & 2,90 & $-0,143$ & $-0,015$ \\
\hline IVF1-5 & 287 & $-0,51$ & $8,09 *$ & 3,47 & $-0,240$ & 0,008 \\
\hline IVF1-6 & -42 & 0,59 & 0,23 & $-0,58$ & 0,234 & 0,022 \\
\hline IVF1-10 & 162 & $-0,51$ & $-3,53$ & $-2,06$ & $1,045^{* *}$ & $-0,043$ \\
\hline IVD1-1 & 69 & 0,37 & $-5,56^{*}$ & $-0,46$ & 0,130 & 0,001 \\
\hline IVD1-2 & 247 & $-0,30$ & $8,50 * *$ & 4,60 & 0,273 & 0,009 \\
\hline IVD1-3 & -431 & $-0,75$ & $-0,89$ & 1,15 & 0,160 & 0,011 \\
\hline IVD1-4 & 17 & 0,25 & $9,94 * *$ & 3,71 & $-0,293$ & $-0,031$ \\
\hline IVD1-5 & -237 & 0,64 & $-1,67$ & $-2,63$ & 0,370 & 0,006 \\
\hline IVD1-8 & 134 & $-0,25$ & $-1,67$ & 2,48 & $-0,405$ & 0,020 \\
\hline IVD1-9 & 202 & 0,03 & $-8,67 * *$ & $-8,85^{*}$ & $-0,235$ & $-0,015$ \\
\hline \multicolumn{7}{|c|}{ Conjunta } \\
\hline IVF1-1 & -149 & $0,35^{*}$ & $-2,815$ & $-2,48$ & $-0,334$ & 0,029 \\
\hline IVF1-2 & -171 & $-0,32 *$ & 2,825 & 1,07 & $-0,251$ & $-0,023$ \\
\hline IVF1-4 & -423 & $0,445^{*}$ & $-5,2$ & $-2,29$ & $-0,063$ & $-0,032$ \\
\hline IVF1-5 & 297 & $-0,82 * *$ & 1,945 & 2,14 & $-0,005$ & 0,033 \\
\hline IVF1-6 & 178 & $0,30 *$ & 1,705 & $-0,69$ & 0,116 & 0,019 \\
\hline IVF1-10 & 268 & 0,04 & 1,54 & 2,25 & $0,537 *$ & $-0,025$ \\
\hline IVD1-1 & 295 & $-0,27$ & $-3,155$ & $-5,51$ & 0,094 & $-0,008$ \\
\hline IVD1-2 & 363 & 0,58 & $7,625^{*}$ & 4,32 & 0,145 & $-0,014$ \\
\hline IVD1-3 & -461 & $-0,75$ & $-0,57$ & 0,99 & 0,063 & 0,016 \\
\hline IVD1-4 & -393 & $-0,08$ & 1,315 & $-1,76$ & $-0,053$ & $-0,018$ \\
\hline IVD1-5 & 251 & $1,05^{*}$ & 0,62 & 5,51 & 0,027 & $-0,003$ \\
\hline IVD1-8 & 83 & 0,00 & $-0,35$ & 5,18 & $-0,131$ & 0,024 \\
\hline IVD1-9 & -137 & $-0,53$ & $-5,49$ & $-8,73$ & $-0,145$ & 0,003 \\
\hline
\end{tabular}

*, ** - Significativamente diferente de zero pelo teste t a 5 e 1\%, respectivamente. 
Tabela 3. Estimativas das Capacidades Específicas de Combinação dos híbridos entre linhagens de milho, oriundas dos compostos Isanão-VF1 e Isanão-VD1, para os caracteres altura de plantas (primeira e segunda safra), altura de espigas (segunda safra) e prolificidade (conjunta para as duas safras), em Selvíria-MS.

\begin{tabular}{|c|c|c|c|c|c|c|c|}
\hline & IVD1-1 & IVD1-2 & IVD1-3 & IVD1-4 & IVD1-5 & IVD1-8 & IVD1-9 \\
\hline \multicolumn{8}{|c|}{ Altura de plantas (cm) - Primeira safra } \\
\hline IVF1-1 & $-3,48$ & 9,35 & $-11,98$ & $-0,26$ & 5,52 & 4,79 & $-3,93$ \\
\hline IVF1-2 & $-0,39$ & $-0,22$ & $-3,56$ & 14,50 & $-0,72$ & $-5,44$ & $-4,17$ \\
\hline IVF1-4 & $-7,87$ & $-16,70$ & $15,97^{*}$ & $-23,64 * *$ & 9,47 & 7,08 & $15,69 * *$ \\
\hline IVF1-5 & 3,42 & 1,92 & $-2,75$ & 5,98 & 1,75 & $-2,30$ & $-8,02$ \\
\hline IVF1-6 & 10,04 & 4,21 & $-3,46$ & $-4,74$ & 6,71 & $-4,02$ & $-8,74$ \\
\hline IVF1-10 & $-1,72$ & 1,44 & 5,78 & 8,17 & $-22,72 * *$ & $-0,11$ & 9,17 \\
\hline \multicolumn{8}{|c|}{ Altura de plantas (cm) - Segunda safra } \\
\hline IVF1-1 & $-9,83^{*}$ & $-10,55^{* *}$ & $31,51^{* *}$ & $-16,66^{* *}$ & $-3,71$ & $20,95^{* *}$ & $-11,71 *$ \\
\hline IVF1-2 & $-17,21 * *$ & 6,74 & $-1,87$ & $11,96^{*}$ & $-13,10 * *$ & $-4,10$ & $17,57^{* *}$ \\
\hline IVF1-4 & $16,65^{* *}$ & 2,60 & $-17,35 * *$ & 6,15 & $-11,57^{*}$ & 7,43 & $-3,90$ \\
\hline IVF1-5 & $16,08^{* *}$ & $-5,31$ & $-5,92$ & $-7,09$ & 4,52 & $-14,48 * *$ & $12,19 *$ \\
\hline IVF1-6 & $-22,40 * *$ & $-2,12$ & 9,27 & 9,10 & 4,05 & 4,05 & $-1,95$ \\
\hline IVF1-10 & $16,70^{* *}$ & 8,64 & $-15,63 * *$ & $-3,47$ & $19,81^{* *}$ & $-13,86^{* *}$ & $-12,19 *$ \\
\hline \multicolumn{8}{|c|}{ Altura de espigas (cm) - Segunda safra } \\
\hline IVF1-1 & $-13,40^{*}$ & $-1,79$ & $13,33^{* *}$ & $-10,56^{*}$ & 1,77 & $13,99 * *$ & $-3,34$ \\
\hline IVF1-2 & $-12,21 *$ & 3,40 & $10,85^{*}$ & 0,29 & $-8,37$ & 0,85 & 5,18 \\
\hline IVF1-4 & 3,94 & 6,88 & $-14,67 * *$ & 8,44 & $-4,90$ & 3,33 & $-3,01$ \\
\hline IVF1-5 & $18,70^{* *}$ & $-7,02$ & $-6,25$ & $-2,13$ & 1,20 & $-11,58^{*}$ & 7,09 \\
\hline IVF1-6 & $-11,25^{*}$ & $-5,64$ & 6,80 & 3,58 & 1,58 & 3,80 & 1,13 \\
\hline IVF1-10 & $14,22 * *$ & 4,17 & $-10,06$ & 0,39 & 8,72 & $-10,39^{*}$ & $-7,06$ \\
\hline \multicolumn{8}{|c|}{ Prolificidade - análise conjunta } \\
\hline IVF1-1 & 0,018 & $-0,006$ & $-0,005$ & $-0,002$ & 0,032 & $-0,062$ & 0,025 \\
\hline IVF1-2 & 0,004 & 0,031 & 0,039 & $-0,005$ & $-0,040$ & $-0,072$ & 0,044 \\
\hline IVF1-4 & 0,027 & 0,070 & 0,046 & $-0,027$ & $-0,024$ & $-0,032$ & $-0,061$ \\
\hline IVF1-5 & $-0,014$ & $-0,008$ & 0,000 & 0,015 & $-0,016$ & 0,031 & $-0,009$ \\
\hline IVF1-6 & $-0,023$ & $-0,025$ & $-0,011$ & 0,012 & 0,011 & $0,086^{*}$ & $-0,050$ \\
\hline IVF1-10 & $-0,012$ & $-0,062$ & $-0,070$ & 0,006 & 0,038 & 0,049 & 0,052 \\
\hline
\end{tabular}

se aproxima muito da condição desejável, com esti- linhagem, a reversão nas atividades dos alelos determativas de CGC favoráveis para todos os caracteres.

Para o grupo IVF1 na segunda safra, considerando os mesmos parâmetros da primeira safra, a linhagem IVF1-10, apesar de apresentar-se desfavorável quanto ao $\mathrm{ACQ}$, merece consideração por sua CGC favorável para RG, FF e AP (Tabela 2). Nessa safra. minantes de AP e AE quando se muda de primeira para segunda safra é nítida, pois tem GCG fortemente positiva na primeira safra e negativa na segunda. Caso não seja prioridade a diminuição de AP e AE, ela pode ser recomendada também para a segunda 
Dentro do grupo IVD1, considerando as melhores linhagens para RG na primeira safra (IVD11 e IVD1-5), uma vez que na segunda todas foram similares, a linhagem IVD1-1 é a que mais se aproxima do ideal, com tendência de maior precocidade, menor AP e AE, embora tenha CGC positiva baixa para ACQ. IVD1-5 apresentou tendência de menor AP e AE apenas na segunda safra, e IVD1-2 tende a ser menos precoce e mais alta. As melhores linhagens para ACQ não são interessantes para os demais caracteres podendo ser consideradas nos casos em que precocidade e arquitetura das plantas não sejam fatores determinantes.

Como os efeitos conjuntos da CEC foram diferentes para PRO e a interação CEC x Safras foi significativa apenas para AP e AE (Tabela 1), a seleção de linhagens deve ser concentrada naquelas com as melhores CGC para RG de cada grupo, buscando-se cruzamentos com melhor CEC para AP, AE e PRO. Assim o cruzamento IVF1-10 x IVD1-5 apresentou a CEC positiva para $\operatorname{PRO}(0,038)$ e fortemente negativa para AP $(-22,72)$ na primeira safra (Tabela 3$)$, embora a CGC de IVF1-10 para AP tenha sido altamente positiva $(6,61)$. Assim, em termos de média do híbrido, o caráter será pouco alterado. Como os efeitos da CEC para AE foram similares nessa safra (Tabela 3), não interferem na abordagem feita para AP. Para a segunda safra, o efeito da CEC inverte-se tanto para AP $(19,81)$ como AE $(8,72)$, por causa da interação, e o híbrido não é o mais recomendado, a não ser apenas com base no RG.

O híbrido IVF1-6 x IVD1-1 se aproxima do ideal para a segunda safra, com CEC negativa para AP $(-22,4)$ e AE $(-11,25)$ embora também negativa para PRO (-0,023). A mesma abordagem pode ser feita para os híbridos IVF1-5 x IVD1-2 e IVF1-6 x IVD1-2, mas com valores menos negativos de CEC para $\operatorname{AP}(-5,31$ e $-7,02$, respectivamente). Como não é possível combinar parâmetros ideais para todos os caracteres, pois esses híbridos apresentam CEC negativa para PRO (Tabela 3), aqueles que mais se aproximam do ideal devem ser considerados.

\section{Conclusões}

Levando em conta apenas o rendimento de grãos, as linhagens indicadas para a obtenção de híbridos para as duas safras são IVF1-5, IVF1-10, IVD1-1 e IVD1-2. Considerando-se todos os caracteres, as linhagens indicadas para a primeira safra são IVF1-6, IVD1-1 e IVD1-5, e para a segunda safra são as linhagens IVF1-10, IVD1-8, e IVD1-9. Os híbridos mais adequados são IVF1-10 x IVD1-5 para primeira safra e IVF1-10 x IVD1-8 e IVF1-10 xIVD1-9 para a segunda.

\section{Referências}

BECK, D. L.; VASAL, S. K.; CROSSA, J. Heterosis and combining ability of CIMMYT's tropical early and intermediate maturity maize (Zea mays L.) germplasm. Maydica, Bergamo, v. 35, n. 3, p. 279-285, 1990.

BENTO, D. A. V.; RAMALHO, M. A. P.; SOUZA, J. C. Seleção massal para a prolificidade na safra normal e na "safrinha". Revista Brasileira de Milho e Sorgo, Sete Lagoas, v. 2, n. 3, p. 78-87, 2003.

DOI: $10.18512 / 1980-6477 /$ rbms.v2n3p78-87.

CANDIDO, L. S.; ANDRADE J. A. C. Breeding potential of maize composite Isanão VF1 in small spacing in the second growing season. Crop Breeding and Applied Biotechnology, Londrina, v. 8, p. 56-64, 2008.

CENTURION, J. F. Balanço hídrico na região de Ilha Solteira. Científica, Jaboticabal, v. 10, n. 1, p. 57-61, 1982. 
CRUZ, C. D. Software GENES: computational application in genetics and statistic. Viçosa, MG: UFV, 2001. 648 p. CRUZ, C. D.; REGAZZI, A. J.; CARNEIRO, P. C. S. Modelos biométricos aplicados ao melhoramento genético. 4. ed. Viçosa, MG: UFV, 2012. v. 1, 514 p.

CRUZ, C. D.; VENCOVSKY, R. Comparação de alguns métodos de análise dialélica. Revista Brasileira de Genética, Ribeirão Preto, v. 12, n. 2, p. 425-436, 1989.

CRUZ, J. C.; QUEIROZ, L. R.; PEREIRA FILHO, I. A. Milho: cultivares para 2012/2013. Disponível em: $<$ http://www.cnpms.embrapa.br/milho/cultivares/index. php>. Acesso em: 17 out. 2013.

DEMATTÊ, J. L. I. Levantamento detalhado dos solos do campus experimental de Ilha Solteira. Piracicaba: ESALQ, 1980. 114 p.

FARINELLI, R.; PENARIOL, F. G.; BORDIN, L.; COICEV, L.; FORNASIERI FILHO, D. Desempenho agronômico de cultivares de milho nos períodos de safra e safrinha. Bragantia, Campinas, v. 62, n. 2, p. 235-241, 2003.

DOI: $10.1590 / \mathrm{S} 0006-87052003000200008$.

FIDELIS, R. R.; MIRANDA, G. V.; FALUBA, J. S. Capacidade de combinação de populações de milho tropicais sob estresse de baixo nitrogênio. Bioscience Journal, Uberlândia, v. 26, n. 3, p. 358-366, 2010.

GORGUlHO, E. P.; MIRANDA FILHO, J. B. Estudo da capacidade combinatória de variedades de milho no esquema de cruzamento dialélico parcial. Bragantia, Campinas, v. 60, n. 1, p. 1-8, 2001.

DOI: 10.1590/S0006-87052001000100001.

GRIFFING, B. Concept of general and specific combining ability in relation to diallel crossing systems. Australian Journal of Biological Science, East Melbourne, v. 9, n. 4, p. 463-493, 1956.

GUIMARÃES, P. S.; PATERNIANI, M. E. A. G. Z.; LUDERS, R. R.; SOUZA, A. P.; LABORDA, P. R.; OLIVEIRA, K. M. Correlação da heterose de híbridos de milho com divergência genética entre linhagens. Pesquisa
Agropecuária Brasileira, Brasília, DF, v. 42, n. 6, p. 811816, 2007. DOI: 10.1590/S0100-204X2007000600007.

HALLAUER, A. R.; MIRANDA FILHO, J. B. Quantitative genetics in maize breeding. Ames: Iowa State University, 1995. 375 p.

JUNG, M. S.; VIEIRA, E. A.; BRANCKER, A.; NODARI, R. O. Capacidade geral e específica de combinação de caracteres do fruto de maracujazeiro doce (Passiflora alata Curtis). Ciência Rural, Santa Maria, v. 37, n. 4, p. 963969, 2007. DOI: 10.1590/S0103-84782007000400007.

KAPPES, C.; ANDRADE, J. A. C.; ARF, O.; OLIVEIRA, A. C.; ARF, M. V.; FERREIRA, J. P. Desempenho de híbridos de milho em diferentes arranjos espaciais de plantas. Bragantia, Campinas, v. 70, n. 2, p. 324-343, 2011.

DOI: $10.1590 / \mathrm{S} 0006-87052011000200012$.

LOCATELLI, A. B.; FEDERIZZI, L. C.; NASPOLINI FILHO, V. Capacidade combinatória de nove linhagens endogâmicas de milho (Zea mays L.) em dois ambientes. Ciência Rural, Santa Maria, v. 32, n. 3, p. 365-370, 2002. DOI: 10.1590/S0103-84782002000300001.

MORELlO, C. L.; MIRANDA FILHO, J. B.; GORGULHO, E. P. Partial diallel cross between exotic and adapted maize populations evaluated in acid soil. Scientia Agricola, Piracicaba, v. 58, n. 2, p. 313-319, 2001.

DOI: $10.1590 / \mathrm{S} 0103-90162001000200014$.

NEVADO, M. E.; CROSS, H. Z. Diallel analysis of relative growth rates in maize synthetics. Crop Science, Madison, v. 30, n. 3, p. 549-552, 1990.

DOI: $10.2135 /$ cropsci1990.0011183X003000030015x.

NIHEI, T.; FERREIRA, J. M. Análise dialélica de linhagens de milho com ênfase na resistência a doenças foliares. Pesquisa Agropecuária Brasileira, Brasília, DF, v. 47, n. 3, p. 369-377, 2012.

DOI: 10.1590/S0100-204X2012000300008.

SANTOS, F. M. C.; FERREIRA, E. A.; GALLO, P. B.; PATERNIANI, A. G. Z. Análise dialélica de híbridos 
simples de milho visando a obtenção de híbridos $\mathrm{F}_{2}$. Revista

Agrotecnologia, Anápolis, v. 4, n. 1, p. 31-45, 2013. SISTEMA brasileiro de classificação de solos. Brasília, DF: Embrapa Produção de Informação; Rio de Janeiro: Embrapa Solos, 1999. 412 p.
VENCOVSKY, R.; BARRIGA, P. Genética biométrica no fitomelhoramento. Ribeirão Preto: Sociedade Brasileira de Genética, 1992. 496 p. 